prior biologic exposures. Importantly, MPC infusions were well-tolerated with no adverse infusion reactions or serious adverse events (SAE) noted over 12 weeks. At 4 and 8 weeks, both MPC groups achieved higher ACR20 levels than placebo, with the placebo group reaching similar levels by 12 weeks. Notably, at 12 weeks both ACR50 rates $(31,27,19 \%)$ and ACR70 rates $(27,20,0 \%)$ were higher for the $2 \mathrm{M} / \mathrm{kg}$ and $1 \mathrm{M} / \mathrm{kg}$ MPC groups than placebo (Figure 1); $\mathrm{p}=0.04$ for ACR70 in $2 \mathrm{M} / \mathrm{kg}$ vs. placebo. The MPC groups showed dose-related greater improvement in pain, patient global assessment (PGA) of disease and physical function vs. placebo with greater efficacy in the $2 \mathrm{M} / \mathrm{kg}$ group (Table 1). At 12 weeks PGA and Pain were significantly reduced in $2 \mathrm{M} / \mathrm{kg} \mathrm{MPC}$ group vs. placebo (both $\mathrm{p}=0.04$ ). MPC treatment was associated with significantly improved health-related physical function by the HAQ. Minimal clinically important difference in $\mathrm{HAQ}$ defined as reduction of at least -0.22 points was achieved in $93 \%$ of $2 \mathrm{M} / \mathrm{kg} \mathrm{MPC}$ vs. $25 \%$ of placebo at 12 weeks $(p=0.003)$

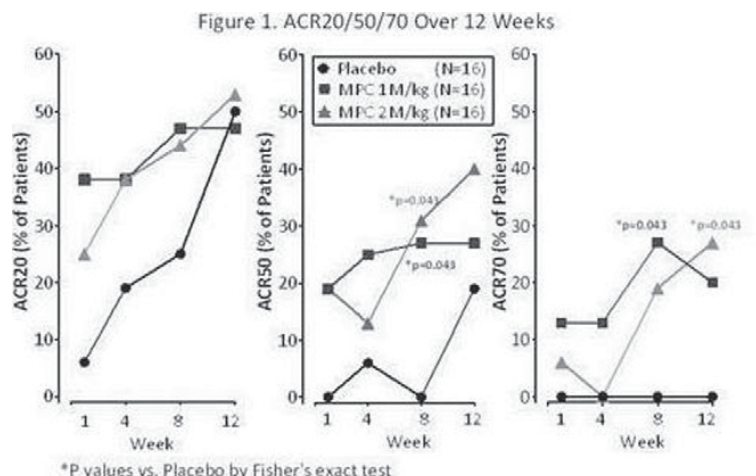

Table 1 Summary of Week 12 Efficacy Assessments

\begin{tabular}{lccc}
\hline & Placebo & MPC 1M/kg & MPC 2M/kg \\
\hline & $\mathrm{N}=16$ & $\mathrm{~N}=16$ & $\mathrm{~N}=16$ \\
ACR20 (\%) & $50 \%$ & $47 \%$ & $50 \%$ \\
ACR50 (\%) & $19 \%$ & $27 \%$ & $31 \%$ \\
ACR70 (\%) & $0 \%$ & $20 \%$ & $27 \%^{*}$ \\
DAS-28 CRP (\%) & & & \\
$\quad$ Response: $\leq 3.2$ & $19 \%$ & $27 \%$ & $36 \%$ \\
$\quad$ Remission: $<2.6$ & $13 \%$ & $20 \%$ & $21 \%$ \\
HAQ Change from baseline $\leq-0.22(\%)$ & $37.5 \%$ & $53 \%$ & $93 \%^{* *}$ \\
ACR Core Components [Change (SE) from baseline] & & \\
$\quad$ Tender joints & $-9.8(1.9)$ & $-5.8(1.9)$ & $-11.2(1.9)$ \\
$\quad$ Swollen joints & $-7.7(1.6)$ & $-6.1(1.6)$ & $-10.1(1.6)$ \\
Investigator global assessment & $-21.6(6.5)$ & $-32.6(6.5)$ & $-35.6(6.6)$ \\
$\quad$ Patient global assessment & $-6.7(6.5)$ & $-17.5(6.5)$ & $-25.7(6.5)^{*}$ \\
$\quad$ Patient pain & $-8.4(6.6)$ & $-16.2(6.6)$ & $-28.6(6.7)^{*}$ \\
\hline P<0.0S: $*$ P<0.005 & & &
\end{tabular}

Conclusions: A single infusion of MPCs was well-tolerated in RA patients. While the efficacy results are encouraging, further assessment including dose optimization is needed. The current trial is a unique early phase trial that shows promise of a future role for MPCs as a therapeutic option in biologic-refractory RA patients, a subset of the RA population with substantial remaining medical need. Disclosure of Interest: S. Kafaja: None declared, K. Segal Employee of: Mesoblast, Inc., D. Skerrett Employee of: Mesoblast, Inc., S. Itescu Employee of: Mesoblast, Inc., D. Furst: None declared

DOI: 10.1136/annrheumdis-2017-eular.1106

\section{FRI0221 DOES SEROPOSITIVITY INFLUENCE DIFFERENTIALLY DRUG DISCONTINUATION OF BIOLOGIC ANTIRHEUMATIC AGENTS WITH NON-ANTI-TNF MODE OF ACTION?}

A. Finckh ${ }^{1}$, D. Courvoisier ${ }^{1}$, J.-E. Gottenberg ${ }^{2}$, X. Mariette $^{3}$, J. Morel ${ }^{4}$, S.A. Bergstra ${ }^{5}$, V. Hernandez ${ }^{6}$, C. Codreanu ${ }^{7}$, T.K. Kvien ${ }^{8}$, M.J. Santos ${ }^{9}$, K. Pavelka ${ }^{10}$, M. Hetland ${ }^{11}$, K. Chatzidionysiou ${ }^{12}$, J. Askling ${ }^{12}$, C. Turesson ${ }^{13}$, C. Gabay ${ }^{1}, \mathrm{R}$. Van Vollenhoven ${ }^{14}$. ${ }^{1} \mathrm{HUG}$, Geneva, Switzerland; ${ }^{2} \mathrm{CHU}$, Strassbourg; ${ }^{3}$ Paris-S University, le Kremlin-Bicêtre; ${ }^{4} \mathrm{CHU}$, Montpellier, France; ${ }^{5}$ University Medical Center, Leiden, Netherlands; ${ }^{6}$ Hospital Clinic, Barcelona, Spain; ${ }^{7}$ Univ of Medicine and Pharmacy, Bucharest, Romania; ${ }^{8}$ Diakonhjemmet Hospital, Oslo, Norway; ${ }^{9}$ Rheuma.PT, Lisbon, Portugal; ${ }^{10}$ Institute of Rheumatology, Prague, Czech Republic; ${ }^{11}$ Glostrup Hospital, Glostrup, Denmark; ${ }^{2}$ Karolinska Institute, Stockholm; ${ }^{13}$ Lund University, Lund, Sweden; ${ }^{14}$ AMC, Amsterdam, Netherlands

Background: Rheumatoid factor (RF) and anti-citrulinated protein antibodies (ACPA) are used as diagnostic tools, but may also be used as prognostic factors or as predictors of response to therapy, as these biomarkers have been associated with better clinical responses to some bDMARDs.

Objectives: To examine whether seropositivity has a similar impact on drug discontinuation of different bDMARDs with a non-anti-TNF mode of action (non-aTNF bDMARDs).

Methods: This is a pooled analysis of 10 observational European RA registries
(FR, CZ, DK, NO, PT, RO, ES, SE, CH, NL). Inclusion criteria were a diagnosis of $R A$, initiation of treatment with abatacept (ABA), rituximab (RTX) or tocilizumab (TCZ) and available information on RF and/or ACPA status. The exposure of interest was seropositivity, which was defined as positive if RF or ACPA was positive and negative if both were negative. The primary endpoint was overall drug discontinuation, defined as the period between treatment initiation and treatment discontinuation. Because national differences may constitute a potential confounder, we only included national registries with information for all 3 bDMARD and pooled data across registries only after excluding significant effect modification by country. Drug discontinuation was analyzed using a Cox proportional hazard model, including drug, seropositivity, and their interaction, adjusting for age, gender, disease duration, baseline DAS28, concomitant synthetic DMARD (sDMARDs), number of previous sDMARDs and bDMARDs, and stratifying by country and calendar year.

Results: We found no effect modification by country, allowing us to pool data from 12040 patients (Table). In crude analyses, seropositivity was associated with a lower drug discontinuation with all 3 bDMARD ( $p$-value interaction 0.22 ), with a hazard ratio for seropositive vs. seronegative (HR) 0.89 (95\% Cl: 0.82-0.97). In adjusted analyses, seropositivity remained associated with a lower drug discontinuation, but the effect differed by drug ( $p$ interaction 0.01): ABA: HR for seropositive vs. seronegative: $0.76(95 \% \mathrm{Cl} 0.66-0.88)$, RTX: $0.88,(95 \%$ Cl: $0.70-1.10)$, and TCZ: $1.08,(95 \% \mathrm{Cl}: 0.89-1.31)$. Two-by-two drug to drug comparisons showed that the effect of seropositivity differed between $A B A$ and TCZ $(p=0.004)$, but not between ABA and RTX $(p=0.29)$, or between TCZ and RTX $(p=0.16)$. Other factors associated with discontinuation were higher baseline disease activity and more previous bDMARD.

\begin{tabular}{|c|c|c|c|}
\hline & $\begin{array}{c}\text { ABA } \\
N=3089\end{array}$ & $\begin{array}{c}\text { RTX } \\
N=5539\end{array}$ & $\begin{array}{c}\mathrm{TCZ} \\
\mathrm{N}=3412\end{array}$ \\
\hline $\begin{array}{l}\text { Seropositivity, } N(\%) \\
\text { RF+ } \\
\text { R } A \text { ACPA+ }\end{array}$ & $\begin{array}{l}2602(84.2 \%) \\
2234(73.0 \%) \\
1861(68.5 \%)\end{array}$ & $\begin{array}{l}5176(93.4 \%) \\
4655(84.1 \%) \\
3703(85.0 \%)\end{array}$ & $\begin{array}{l}2920(85.6 \%) \\
2682(79.3 \%) \\
1826(73.7 \%)\end{array}$ \\
\hline Female sex, $\mathrm{N}(\%)$ & $2463(79.7 \%)$ & $4543(82.0 \%)$ & $2692(78.9 \%)$ \\
\hline & $56.8(1$ & $58.9(12.1)$ & $55.9(12.8)$ \\
\hline Disease d & $11.8(9.3)$ & $12.5(9.3)$ & $11.2(9.6)$ \\
\hline DAS28 at bas & $4.9(1.5)$ & $5.2(1.5)$ & $4.7(1.4)$ \\
\hline N previous SDMARD, $\mathrm{N}(\%)$ & & & \\
\hline $\begin{array}{l}\leq 1 \\
\geq 2\end{array}$ & $\begin{array}{l}917(32.3 \%) \\
1925(67.7 \%)\end{array}$ & $\begin{array}{l}1988(40.1 \%) \\
2972(59.9 \%)\end{array}$ & $\begin{array}{l}1245(39.2 \%) \\
1928(60.8 \%)\end{array}$ \\
\hline $\mathrm{N}$ previous bDMARD, $\mathrm{N}(\%)$ & & & \\
\hline $\begin{array}{l}\leq 1 \\
\geq 2\end{array}$ & $1903(62.1 \%)$ & $3818(69.2 \%)$ & $1733(52.5 \%)$ \\
\hline & & & \\
\hline $\begin{array}{l}\text { Concomitant sDMARD, N }(\%) \\
\text { Median follow-up time [yrs] }\end{array}$ & $1657(53.6 \%)$ & $3899(70.5 \%)$ & $2251(66.1 \%)$ \\
\hline $\begin{array}{l}\text { Calendar year of treatment } \\
\text { initiation, } 10^{\mathrm{th}}-90^{\mathrm{th}} \text { percentile }\end{array}$ & $2008-2014$ & $2006-2012$ & $2009-2015$ \\
\hline
\end{tabular}

Conclusions: Data from this pooled european registry analysis suggests that seropositivity is associated with lower drug discontinuation of non-aTNF bDMARDs. This effect differed between drugs and was significant for ABA, but not for TCZ or RTX. The impact of seropositivity on other measures of effectiveness still needs to be investigated.

Disclosure of Interest: A. Finckh Grant/research support from: BMS, Speakers bureau: Abbvie, Roche, Pfizer, UCB, D. Courvoisier: None declared, J.-E. Gottenberg: None declared, X. Mariette: None declared, J. Morel: None declared, S. A. Bergstra: None declared, V. Hernandez: None declared, C. Codreanu Grant/research support from: Abbvie, Pfizer, Roche, Consultant for: MSD, Pfizer, Roche, Paid instructor for: Abbvie, Bristol-Myers Squibb, Janssen, MSD, Pfizer, Roche and UCB, T. K. Kvien: None declared, M. J. Santos: None declared, K. Pavelka: None declared, M. Hetland Grant/research support from: AbbVie, BMS, MSD, Biogen, UCB, Pfizer, Eli Lilly, Roche, Speakers bureau: Orion, K. Chatzidionysiou Consultant for: AbbVie, Pfizer, Eli Lilly, UCB, Roche, J. Askling Grant/research support from: Abbvie, UCB, Lilly, Janssen, Samsung, Pfizer, MSD, Roche, C. Turesson Grant/research support from: Abbvie, Pfizer, Roche, Consultant for: MSD, Pfizer, Roche, Paid instructor for: Abbvie, Bristol-Myers Squibb, Janssen, MSD, Pfizer, Roche and UCB, C. Gabay: None declared, R. Van Vollenhoven: None declared

DOI: 10.1136/annrheumdis-2017-eular.6006

\section{FRI0222 SUSTAINED RESPONSE FOLLOWING DISCONTINUATION OF METHOTREXATE IN PATIENTS WITH RHEUMATOID ARTHRITIS TREATED WITH SUBCUTANEOUS TOCILIZUMAB: RESULTS FROM A RANDOMIZED CONTROLLED TRIAL (COMP-ACT)}

J. Kremer $^{1}$, W. Rigby ${ }^{2}$, N. Singer ${ }^{3}$, C. Birchwood ${ }^{4}$, D. Gill ${ }^{4}$, W. Reiss ${ }^{4}$, J. Pei $^{4}$, M. Michalska ${ }^{4} .{ }^{1}$ Albany Medical College and The Center for Rheumatology, Albany, NY; ${ }^{2}$ Geisel School of Medicine, Dartmouth College, Lebanon, NH; ${ }^{3}$ School of Medicine, MetroHealth System, Case Western Reserve University, Cleveland, $\mathrm{OH} ;{ }^{4}$ Genentech, Inc., South San Francisco, CA, United States

Background: Methotrexate (MTX) is frequently administered in combination with biologics for the treatment of rheumatoid arthritis (RA). MTX may be subsequently discontinued due to intolerance or nonadherence, and/or to reduce medication burden once disease control is achieved. Previous studies have established the efficacy of tocilizumab (TCZ) initiated as monotherapy (MONO), but the impact 
of MTX withdrawal in patients achieving good clinical response to TCZ+MTX (COMBO) has not been evaluated.

Objectives: To evaluate whether TCZ-MONO is non-inferior to TCZ-COMBO in maintaining clinical response in patients who achieve low disease activity with TCZ-COMBO.

Methods: US patients with RA who were inadequate responders to MTX were enrolled: initial combination therapy included MTX (15 mg/week orally) plus TCZ $162 \mathrm{mg}$ subcutaneous (SC) either weekly (qw; for patients $\geq 100 \mathrm{~kg}$ ) or every 2 weeks (q2w; for patients $<100 \mathrm{~kg}$ ). Dose escalation from q2w to qw was allowed at week 12 in patients who had not achieved low disease activity (DAS28 $\leq 3.2$. If patients achieved DAS28-ESR $\leq 3.2$ at week 24 , they were randomized (double-blind) 1:1 to receive either TCZ-MONO or continue TCZ-COMBO until week 52. Patients who did not achieve DAS28 $\leq 3.2$ were assigned to an open-label arm and continued TCZ-COMBO until week 52. The primary outcome measured was the comparison of mean change in DAS28-ESR score in the randomized cohort between weeks 24 and 40, between the TCZ-MONO or TCZ-COMBO arms (noninferiority margin of 0.6 ). Secondary outcomes included the proportion of patients achieving DAS28 $<2.6$, DAS28 $<3.2$ and American College of Rheumatology $20 \% / 50 \% / 70 \%$ (ACR20/50/70) responses at weeks 40 and 52, and safety. Trial registration number: NCT01855789.

Results: Of 718 patients enrolled, 296 were randomized at week 24 (TCZ-MONO, $n=148$; TCZ-COMBO, $n=148$ ). Early discontinuation in the randomized cohort occurred in $12.2 \%$ of patients in the TCZ-MONO group and $10.2 \%$ in the TCZ-COMBO group. Baseline characteristics were balanced between treatment groups (mean age 55.5 years; $74.8 \%$ female; mean RA duration 6.8 years; mean DAS28-ESR 6.3). At week 24, DAS28 scores were similar in both groups, but ACR responses were $\sim 8-11 \%$ lower in the TCZ-MONO group prior to MTX withdrawal (randomization). The mean change in DAS28 was similar between the randomized treatment groups (Table 1). For the primary efficacy analysis, the mean changes in DAS28 from week 24 to week 40 were 0.46 and 0.14 in the TCZ-MONO and TCZ-COMBO groups, respectively (95\% Cl: $0.045-0.592)$. This study met the primary endpoint by demonstrating that discontinuing MTX in TCZ responders was noninferior to continuing MTX. The safety of TCZ-SC in this study was consistent with the known safety profile with no new safety signals observed (Table 2). The most common SAE was infection, occurring in $4.1 \%$ of patients. TCZ-COMBO had greater frequency of AEs, SAEs and serious infections than TCZ-MONO.

\begin{tabular}{|c|c|c|c|c|}
\hline & $\begin{array}{c}\text { TCZ-MONO } \\
n=147\end{array}$ & $\begin{array}{c}\text { TCZ-COMBO } \\
n=147\end{array}$ & \multicolumn{2}{|c|}{$\begin{array}{c}\text { Difference }(95 \% \mathrm{Cl}) \\
\text { (TCZ-MONO minus } \\
\text { TCZ-COMBO) }\end{array}$} \\
\hline \multicolumn{5}{|c|}{$\triangle \mathrm{DAS} 28-\mathrm{ESR}$, Mean $(\mathrm{SEM})^{\star}$} \\
\hline Week 24 to week 40 & $0.46(0.123)$ & $0.14(0.126)$ & \multirow{2}{*}{\multicolumn{2}{|c|}{ 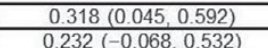 }} \\
\hline Week 24 to week 52 & $0.43(0.136)$ & $0.20(0.139)$ & & \\
\hline \multicolumn{5}{|c|}{ Response at Week $40, \mathrm{n}(\%)$} \\
\hline DAS28 $\leq 3.2$ & $94(63.9)$ & $113(76.9)$ & \multicolumn{2}{|c|}{$-12.9(-23.3,-2.6)$} \\
\hline DAS28 $<2.6$ & $74(50.3)$ & $87(59.2)$ & \multicolumn{2}{|c|}{$-8.8(-20.2,2.5)$} \\
\hline ACR20 & $103(70.1)$ & $116(78.9)$ & \multicolumn{2}{|c|}{$-8.8(-18.8,1.1)$} \\
\hline ACR50 & $76(51.7)$ & $94(63.9)$ & \multicolumn{2}{|c|}{$-12.2(-23.4,-1.0)$} \\
\hline ACR70 & $51(34.7)$ & $62(42.2)$ & \multicolumn{2}{|c|}{$-7.5(-18.6,3.6)$} \\
\hline \multicolumn{5}{|c|}{ DAS28 Worsening $\geq 1.2, \mathrm{n}(\%)$} \\
\hline Week 24 to week 40 & $42(28.6)$ & $31(21.1)$ & \multicolumn{2}{|c|}{$7.5(-2.4,17.3)$} \\
\hline \multicolumn{5}{|c|}{$\begin{array}{l}\text { ACR, American College of Rheumatology criteria; AE, adverse event; } \triangle \mathrm{DAS} 28 \text {-ESR, change in Disease } \\
\text { Activity Score-28 joints erythrocyte sedimentation rate; MTX, methotrexate; SAE, serious adverse } \\
\text { events; SEM, standard error of the mean; TCZ-COMBO, tocilizumab plus MTX; TCZ-MONO, TCZ } \\
\text { monotherapy. } \\
\text { *Adjusted means from ANCOVA model include week } 24 \text { DAS28 as a covariate, treatment group and the } \\
\text { randomization stratification factors: DAS2 } 28 \text { remission status at week } 24(<2.6 ; \geq 2.6 \text { to } \leq 3.2) \text {, patient } \\
\text { anti-TNF exposure (Yes/No), baseline weight-by-dosing group ( }<80 \mathrm{~kg} q 2 \mathrm{w} ;<80 \mathrm{~kg} \text { qw; } 80 \text { to }<100 \mathrm{~kg} \\
\text { q2w, } 80 \text { to }<100 \mathrm{~kg} q w, \geq 100 \mathrm{~kg} \text { qw). Last observation carried forward (LOCF) was used to impute } \\
\text { missing data at week } 40 \text { only. } \\
\text { Table 2. Safety of TCZ as Monotherapy and in Combination With MTX }\end{array}$} \\
\hline $\begin{array}{l}\text { Rate, per } 100 \mathrm{PY} \\
(95 \% \mathrm{Cl})\end{array}$ & $\begin{array}{c}\text { Total }^{*} \\
N=713 \\
700.60 \mathrm{PY}\end{array}$ & $\begin{array}{r}\text { TCZ-M } \\
n=1 \\
92.44\end{array}$ & $\begin{array}{l}\mathrm{NO}^{\dagger} \\
44 \\
\mathrm{PY}\end{array}$ & $\begin{array}{c}\text { TCZ-COMBO }^{\dagger} \\
n=139 \\
90.56 \mathrm{PY}\end{array}$ \\
\hline AEs & $\begin{array}{c}377.1 \\
(362.9,391.8\end{array}$ & $\begin{array}{r}238 \\
(207.6\end{array}$ & $271.6)$ & $\begin{array}{c}308.1 \\
(273.0,346.4)\end{array}$ \\
\hline SAES & $\begin{array}{c}17.0 \\
(14.1,20.3)\end{array}$ & $\begin{array}{r}8.7 \\
(3.7 .1\end{array}$ & & $\begin{array}{c}14.4 \\
(7.6,24.6)\end{array}$ \\
\hline Serious infections & $\begin{array}{c}5.0 \\
(3.5,7.0)\end{array}$ & $\begin{array}{r}3 . \\
(0.7 \\
\end{array}$ & & $\begin{array}{c}4.4 \\
(1.2,11.3)\end{array}$ \\
\hline
\end{tabular}

t Includes all randomized patients who received TCZ+MTX or TCZ+PBO from week 24 to end of study

Conclusions: These results demonstrate that patients receiving TCZ-COMBO who achieve low disease activity can discontinue MTX and maintain disease control.

Acknowledgements: This study was funded by F. Hoffmann-La Roche, Ltd. Disclosure of Interest: J. Kremer Shareholder of: Corrona, LLC, Consultant for: AbbVie; Amgen; Bristol-Meyers Squibb; Genentech; GlaxoSmithKline; Eli Lilly; Pfizer; Regeneron; Sanofi, Employee of: Corrona, LLC, W. Rigby Consultant for: Roche, N. Singer Grant/research support from: Merck, EMD Serono, Consultant for: Pfizer, C. Birchwood Employee of: Genentech, Inc., D. Gill Employee of: Genentech, Inc., W. Reiss Employee of: Genentech, Inc., J. Pei Employee of: Genentech, Inc., M. Michalska Employee of: Genentech, Inc.

DOI: 10.1136/annrheumdis-2017-eular.2797

\section{FRI0223 ANTI-CCP IS AN INDEPENDENT PREDICTOR OF 12-MONTH EULAR RESPONSE IN PATIENTS WITH RA TREATED WITH ABATACEPT}

A. den Broeder ${ }^{1}$, T. Kerstens ${ }^{2}$, J. Fransen ${ }^{2}$, C. van den Ende ${ }^{1}$,

L. Tweehuysen ${ }^{3}$, R. Postema ${ }^{4}$, E. Alemao ${ }^{5}$, F. van den Hoogen ${ }^{2} .{ }^{1}$ Sint Maartenskliniek and Radboud UMC; ${ }^{2}$ Radboud UMC; ${ }^{3}$ Sint Maartenskliniek, Nijmegen, Netherlands; ${ }^{4}$ Bristol-Myers Squibb, Uxbridge, United Kingdom;

${ }^{5}$ Bristol-Myers Squibb, Princeton, United States

Background: Although anti-cyclic citrullinated peptide (anti-CCP) positivity is regarded as a strong prognostic factor for untreated RA outcome, the benefit of anti-CCP tests for personalized medicine is controversial. ${ }^{1}$ Illustratively, anti-CCP was not predictive for response to anti-TNF in RA, as shown in meta-analyses, although some predictive value was shown for rituximab. ${ }^{2-4}$ There are, however, indications that better response to abatacept (ABA) is predicted by anti-CCP positivity. ${ }^{5-7}$

Objectives: To test whether anti-CCP level at baseline $(B L)$ is an independent predictor for treatment response (DAS28 [CRP]-based EULAR response criteria) at 12 months $(M)$ in patients (pts) with RA treated with $A B A$.

Methods: Consenting pts with RA from Radboud UMC and Sint Maartenskliniek were consecutively included if they started treatment with $A B A(B L)$. The anti-CCP values closest before BL were used. DAS28 (CRP) was assessed at BL and at $12 \mathrm{M}$ by trained rheumatology nurses or rheumatologists. Demographic and disease-related variables, treatment history and co-morbidity were also assessed. Primary outcome was response to treatment based on DAS28 (CRP) EULAR response criteria at M12. Therapy cessation was regarded as non-response. Multiple imputation with 20 repetitions was used to replace missing predictors. Multivariate logistic regression was used to examine whether anti-CCP positivity was an independent predictor for treatment response, taking confounding $\mathrm{BL}$ covariates (Table variables) into account.

Results: Data were available for 200 pts with RA starting ABA. Mean (SD) age was 58 (13) years, $165(83 \%)$ were female and median (p25-p75) disease duration was 12 (7-19) years (Table). Overall, $121(61 \%)$ pts were anti-CCP positive at BL. At 12M, 86 (43\%) pts remained on ABA. In the univariate model, anti-CCP was a predictor for treatment response (odds ratio $2.51 ; 95 \% \mathrm{Cl} 1.1$, $6.0 ; p=0.038$ ). No relevant confounding was present.

Table 1. Baseline Characteristics

\begin{tabular}{lc}
\hline & Abatacept $(\mathrm{n}=200)$ \\
\hline Age, years, mean (SD) & $58(13)$ \\
Female, $\mathrm{n}(\%)$ & $165(83)$ \\
$\mathrm{RF}+, \mathrm{n}(\%)$ & $128(64)$ \\
Anti-CCP+, $\mathrm{n}(\%)$ & $121(61)$ \\
No. of previous bDMARDs & $3(3-4)$ \\
No. of previous csDMARDs & $3(2-4)$ \\
Oral glucocorticoids, $\mathrm{n}(\%)$ & $79(40)$ \\
Disease duration, years & $12(7-19)$ \\
Treatment duration, months & $8(4-28)$ \\
NSAID, $\mathrm{n}(\%)$ & $117(59)$ \\
Concomitant DMARD, $\mathrm{n}(\%)$ & $117(59)$ \\
Overweight (BMI $\left.>25.0 \mathrm{~kg}^{\star} \mathrm{m}^{2}\right), \mathrm{n}(\%)$ & $98(48)$ \\
\hline
\end{tabular}

${ }^{*}$ Median (p25-p75). RF+: IgM-Rheumatoid factor positivity. b/csDMARD=biologic/conventional synthetic DMARD.

Conclusions: Anti-CCP positivity was confirmed as an independent predictor for treatment response at $12 \mathrm{M}$ in pts with RA treated with abatacept. As indicated by meta-analysis and systematic reviews, anti-CCP is not predictive for the response to anti-TNFs. ${ }^{2-4}$ Additional studies are needed to evaluate whether abatacept could be a preferable treatment in anti-CCP-positive pts.

References:

[1] Taylor P, et al. Autoimmune Dis 2011;2011:815038.

[2] Lv Q, et al. PLoS ONE 2014:9:e89442.

[3] Isaacs JD, et al. Ann Rheum Dis 2013;72:329-36.

[4] Cuppen BV, et al. Rheumatology (Oxford) 2016;55:826-39.

[5] Gottenberg JE, et al. Ann Rheum Dis 2012;71:1815-19.

[6] Sokolove J, et al. Ann Rheum Dis 2015;74(Suppl 2):675.

[7] Huizinga TWJ, et al. Ann Rheum Dis 2015;74(Suppl 2):234-5.

Disclosure of Interest: A. den Broeder Grant/research support from: CZ, Menzis, ZonMw, Consultant for: Amgen, Boehringer Ingelheim, Speakers bureau: BristolMyers Squibb, Pfizer, T. Kerstens: None declared, J. Fransen Grant/research support from: Bristol-Myers Squibb, C. van den Ende: None declared, L. Tweehuysen: None declared, R. Postema Employee of: Bristol-Myers Squibb, E. Alemao Shareholder of: Bristol-Myers Squibb, Employee of: Bristol-Myers Squibb,

F. van den Hoogen Consultant for: Celltrion, Sandoz, Mundipharma and Biogen, Speakers bureau: Celltrion, Sandoz, Janssen, Egis

DOI: 10.1136/annrheumdis-2017-eular.2477 